\title{
Anorexia nervosa, cognitieve zwaktes en sterktes
}

\author{
Guido Pieters • Wouter Hulstijn • Yvonne Maas • \\ Walter Vandereycken • Joseph Peuskens • Michel Probst • \\ Bernard Sabbe
}

Keywords anorexia nervosa $\cdot$ cognitief functioneren

Velen veronderstellen dat bij patiënten met anorexia nervosa cognitieve processen gestoord zijn, waarschijnlijk omdat zij er zulke vreemde opvattingen op na houden over hun gewicht en hun voorkomen. Zij zouden cognitieve beperkingen hebben zolang ze mager zijn. Dit hebben wij onderzocht. Patiënten werden getest met kopieertaken. Deze werden afgenomen bij sterk ondergewicht en na gewichtsherstel. Bovendien werden ze afgenomen bij controleproefpersonen. In de kopieertaken vertoonden de anorexiapatiënten kortere reactietijden dan de controles, zowel bij uitgesproken ondergewicht als na gewichtsherstel. We vonden dus geen aanwijzingen voor cognitieve tekorten, gerelateerd aan executief functioneren, bij anorexia-nervosapatiënten. Patiënten vertoonden aanwijzingen voor superieure planning en sequencing-capaciteit, zowel bij uitgesproken ondergewicht als na gewichtsherstel. Deze bevindingen zijn in overeenstemming met de hypothese dat een sterke cognitieve activering, een 'mentale bewegingsdrang', karakteristiek is voor acute anorexia nervosa.

\section{Inleiding}

Anorexia nervosa (AN) is een stoornis die vooral bij jonge vrouwen voorkomt en een prevalentie heeft van ongeveer $0,3 \%$ bij vrouwen tussen 15 en 25 jaar. Het gaat om een stoornis met een slechte prognose en nog steeds een hoge mortaliteit (10 maal hoger dan van de vergelijkbare populatie).

Sinds de vroegste beschrijvingen van het syndroom op het einde van de $19 \mathrm{e}$ eeuw werden onderzoekers en

behandelaars getroffen door de discrepantie tussen het extreme ondergewicht en het uitgemergelde aspect van anorexiapatiënten enerzijds en hun hoge fysieke en mentale activiteit anderzijds (Van Deth \& Vandereycken, 1988). Hilde Bruch (1973), een van de pioniers in de studie en behandeling van deze stoornis, gebruikte de term 'hyperalertheid' om de mentale/cognitieve tegenhanger van de vaak beschreven fysieke hyperactiviteit bij deze patiënten te beschrijven. Deze verhoogde alertheid, die wel eens wordt beschreven bij vrouwen in de eerste fase van een vermageringsdieet, staat in schril contrast met de cognitieve en motorische vertraging die men ziet bij mensen die om andere redenen veel gewicht hebben verloren. Wetenschappelijk onderzoek hierover is om ethische redenen niet goed mogelijk. Vergelijkingen met mensen die wegens een somatische stoornis of ten gevolge van hongersnood of gevangenschap gewicht verloren, is niet bruikbaar omdat de bijkomende omstandigheden heel verschillend zijn en ook invloed kunnen uitoefenen. Op dit ogenblik hoopt men door de studie van mensen die vrijwillig hun calorie-inname beperken om hun levensduur te verlengen (bekend als caloric restriction for longlevity) een inzicht te krijgen in de rol die caloriebeperking en andere kernsymptomen van AN daarbij spelen. Deelnemers aan reality programma's zoals Expeditie Robinson, of hongerstakers voor politieke doeleinden vertonen vaak reeds na een korte tijd acuut hongeren een sterke motorische en mentale vertraging.

De bevindingen uit neuropsychologisch onderzoek bij eetstoornispatiënten, en bij anorexiapatiënten in het bijzonder, zijn tegenstrijdig (Southgate e.a., 2005). Meestal vindt men dat de patiënten slechter functioneren op het gebied van allerlei cognitieve functies zoals aandacht, geheugen, planning of set shifting (verandering van 
strategie) en een extreme rigiditeit vertonen. Toch wordt er in heel wat studies geen verschil gevonden tussen patiënten en controles op een aantal van de genoemde neuropsychologische functies. Ten slotte zijn er vooral recent een aantal opmerkelijke rapporten verschenen die de superioriteit van patiënten op een aantal vlakken van neuropsychologisch functioneren beschrijven. Daarbij gaat het vaak om jongere patiënten en om sensorimotorische taken.

Geïntrigeerd door hogergenoemde bevindingen en geïnspireerd door een traditie van psychomotorisch onderzoek bij eetstoornispatiënten in het Universitair Centrum St. Jozef te Kortenberg, België, besloten we het psychomotorisch functioneren van anorexiapatiënten nauwkeurig te bestuderen. Daarbij maakten we gebruik van kennis en methodologie uit het onderzoeksgebied van de depressie. Deze stoornis vertoont veel comorbiditeit met AN, en er zijn ook neuro-endocriene overeenkomsten tussen de stoornissen (bijvoorbeeld een hyperactieve HPA-as). Bij depressieve patiënten ziet men vooral psychomotorische vertraging, maar soms wordt ook agitatie beschreven. In dit onderzoeksgebied werd gebruikgemaakt van kopieertaken, waarbij kenmerken van de fijne motoriek nauwgezet werden bestudeerd door middel van een schrijftablet of digitizer (Sabbe e. a., 1999; Sabbe \& Hulstijn, 2001). In ons eigen onderzoek (Pieters e.a., 2003; Pieters e.a., 2004; Pieters e.a., 2005; Pieters e.a. in press) besloten we om deze methodologie ook te gebruiken bij anorexiapatiënten om hun sensorimotorisch functioneren te bestuderen.

In dit onderzoek werden de volgende onderzoeksvragen behandeld. Zijn anorexiapatiënten sneller in het uitvoeren van fijne motorische taken dan jonge vrouwen zonder eetproblemen? Indien dat het geval is, wat is dan de aard van het verschil: gaat het meer om cognitieve processen zoals aandacht, geheugen of planning, of gaat het meer om motorische processen met betrekking tot de controle en de uitvoering van tekenbewegingen? En wat is het effect van gewichtsherstel op deze processen?

\section{Het onderzoek}

Grafische taken maken deel uit van een zeer groot aantal neuropsychologische tests om allerlei processen te meten zoals visuospatiële vaardigheden, visueel werkgeheugen, planning en sequencing. Schrijven en tekenen zijn veelgebruikte vaardigheden die goed bruikbaar zijn voor onderzoek omdat ze precies en op een niet interfererende manier kunnen worden geregistreerd en omdat allerlei mogelijk relevante variabelen (bijvoorbeeld de complexiteit van de te kopiëren stimulus) gemakkelijk kunnen worden gemanipuleerd. Ten slotte zijn activiteiten als tekenen en kopiëren ook in het dagelijks leven belangrijk. In dit onderzoek werd daarom gebruikgemaakt van teken- en kopieertaken.

In een gecontroleerde studie namen 32 anorexiapatiënten tussen 15 en 25 jaar deel (rechtshandig, niet psychotisch, zonder misbruik van middelen en zonder neurologisch trauma). Daarnaast werden 32 controles onderzocht, gematcht voor leeftijd en opleidingsniveau, die geen eetstoornis vertoonden (BMI boven 19, en scores op eetstoornisvragenlijsten binnen normale grenzen). Zeventien van de 32 patiënten bereikten gewichtsherstel, gedefinieerd als een BMI groter of gelijk aan $18,5 \mathrm{~kg} / \mathrm{Ze}$ deden dit na een interval van gemiddeld $130(+/-40)$ dagen. De controleproefpersonen werden getest na een gelijksoortig interval. Bij patiënten en controles werd een aantal vragenlijsten afgenomen, om algemene psychopathologie, depressie, meer specifieke eetstoornispathologie te evalueren.

Bij de kopieertaak werden de figuurtjes die nagetekend moesten worden, gepresenteerd op een computerscherm. Zodra de proefpersonen begonnen te tekenen, verdwenen figuurtjes, zodat zij dus uit het geheugen

Figuur 1 De kopieertaak; een schrijftablet en een computerscherm

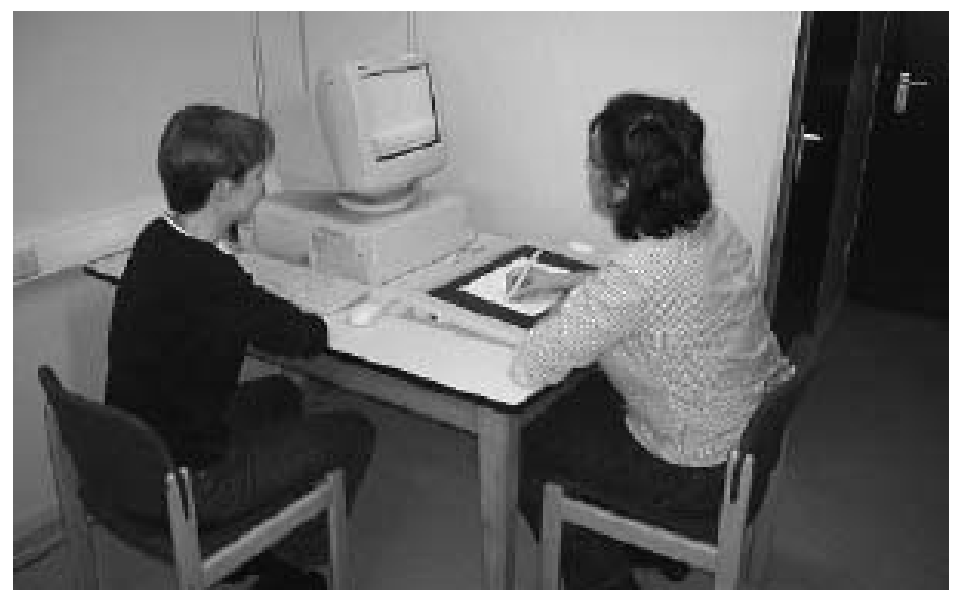


nagetekend moesten worden. De proefpersonen tekenden op een vel papier, geplaatst op een schrijftablet (figuur 1).

Figuur 2 De Symbol Digit Modality test controles: ze slaagden erin in 90 seconden duidelijk meer cijfers aan het juiste symbooltje te koppelen. Dit verschil werd volledig verklaard door het verschil in de zoektijd
In deze opstelling werden twee klassieke neuropsychologische taken afgenomen: de 'Symbol Digit Modality Test' en de 'Trailmaking Test'. Daarnaast twee heel simpele tekentaken en ten slotte vier kopieertaken, waarbij proefpersonen gevraagd werd om zo snel en zo accuraat mogelijk lijntjes, simpele figuren of meer complexe figuren te kopiëren. Ten slotte werden figuurtjes voorgelegd waarbij conflicten tussen impliciete productieregels werden opgeroepen (zie verder). Waar de meest simpele taken meer informatie bieden over basale motorische snelheid (de tekensnelheid), hebben de complexere taken ook meer betrekking op cognitieve processen zoals aandacht, geheugen en planning van acties en beweging.

Figuur 2 toont de Symbol Digit Modality test, waarbij aan de hand van een sleutel bij een reeks symbooltjes het bijhorend cijfer dient te worden geschreven. De opdracht luidt in 90 seconden zo veel mogelijk juiste cijfers te noteren. Daarbij wordt onderscheid gemaakt tussen de zoektijd (de tijd dat de pen boven het papier zweeft of op het papier stilstaat) en de tekentijd (tijd die nodig is om de cijfers op te schrijven). Deze taak geeft een idee over informatieverwerkingssnelheid, geheugen en strategie. In deze taak scoorden patiënten significant beter dan de die bij patiënten significant korter was. De tekentijd verschilde niet tussen de groepen.

Figuur 3 toont de stimuli, gebruikt bij de kopieertaken. Naarmate de te kopiëren stimulus ingewikkelder wordt, is er meer cognitieve belasting van geheugen en planning. Bij de 'complexe figuren' (onderste drie rijen) bestaan de linkse stimuli telkens uit vier halen, terwijl stimuli aan de rechterkant complexer zijn, omdat ze uit acht halen bestaan. Ook de vertrouwdheid met de te kopiëren stimuli werd gemanipuleerd.

Enerzijds zijn er hoofdletters, die goed bekend zijn en dus gemakkelijk te onthouden, en die al vaak opgeschreven zijn. Er is dus een ingeslepen motorisch plan voorhanden en over de volgorde van de halen hoeft niet te worden 'nagedacht'. Daarnaast zijn er figuren die goed herkenbaar zijn en ook gemakkelijk herinnerd kunnen worden, maar die meestal nog niet getekend zijn: er moet dus een nieuw motorisch plan worden ontworpen, de volgorde van de halen vraagt enige planning. Ten slotte zijn er de patronen die volledig nieuw zijn en dus meer inspanning vragen voor herkenning en geheugen en die evenmin getekend zijn en dus ook meer planningsactiviteit vragen.
Figuur 3 Figuren die gebruikt werden voor de kopieertaken, van eenvoudig naar complex

\begin{tabular}{|c|c|c|c|c|}
\hline lines & | & 一 & $>$ & $<$ \\
\hline $\begin{array}{l}\text { sample } \\
\text { figures }\end{array}$ & 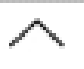 & & & \\
\hline complex figures & \multicolumn{2}{|c|}{4 strokes } & \multicolumn{2}{|c|}{8 strokes } \\
\hline letters & ZI & $L$ & $\mathrm{AL} Z$ & ETL \\
\hline figures & $\Rightarrow$ & $\square$ & $\square$ & $\pi$ \\
\hline patterns & & 1 & & $D$ \\
\hline
\end{tabular}


Figuur 4 De kopieertaak voor het meten van het effect van conflicterende impliciete productieregels

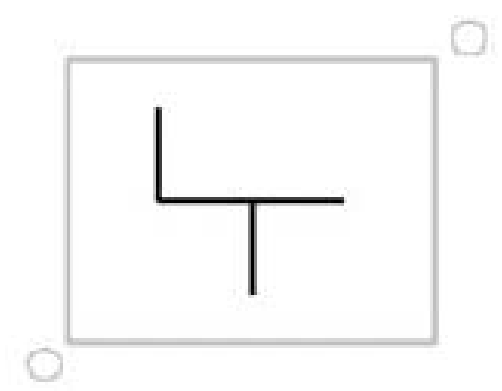

Planningsproblemen verraden zich vooral in de reactie- of opstarttijd en dat vooral bij niet-geoefende figuurtjes en patronen, en nog meer als deze figuurtjes en patronen uit meer halen bestaan en dus complexer zijn.

Uit ons onderzoek bleek dat bij de kopieertaken (figuur 3) patiënten significant kortere reactietijden hadden dan controles, terwijl de tekentijd niet verschilde. Dit patroon deed zich voor bij alle kopieertaken. Wanneer we de reactietijden bij het kopiëren van complexe figuren bekijken dan zien we dat anorexiapatiënten vooral sneller reageren dan controles bij meer complexe figuren (die bestaan uit acht halen). Deze complexe figuren betekenen een grotere belasting zowel voor het geheugen als voor planningsprocessen. We zien eveneens een vertrouwdheidseffect: patiënten hebben vooral een kortere reactietijd bij figuren en patronen, minder bij hoofdletters. Deze laatste zijn vaak ingeoefend en vragen minder planning. Wanneer echter figuren en patronen moeten worden nagetekend vraagt dat juist meer planning. De resultaten wijzen dus bij patiënten in de richting van betere planningsmogelijkheden. Wel moet hieraan worden toegevoegd dat anorexiapatiënten op deze taken soms wat minder nauwkeurig zijn en dat een verhoogde snelheid misschien ten koste gaat van de zorgvuldigheid, waardoor meer fouten worden gemaakt.

In een laatste kopieertaak bekeken we het effect van conflicten tussen impliciete productieregels. Wanneer we tekenen is ons grafisch gedrag onderhevig aan impliciete productieregels die mede cultureel bepaald zijn. Deze hebben betrekking op startpunt, tekenrichting en tekenvolgorde. Zo tekenen we in onze cultuur bijvoorbeeld liefst van boven naar beneden en van links naar rechts, rijgen we de halen zo veel mogelijk aaneen en als we de pen toch van het papier moeten opheffen, vertrekken we van een punt op reeds bestaande lijnen ('ankeren'). Evenwijdige lijntjes worden direct na mekaar getekend. In de linkerfiguur in figuur 4 zijn deze regeltjes probleemloos te volgen. De figuur rechts lokt een conflict uit tussen deze regels. Deze figuurtjes zijn elkaars spiegelbeeld en de geheugenbelasting is dus identiek en wegens de eenvoud van de figuurtjes beperkt. Toch is er bij het kopiëren een verschil in cognitieve belasting tussen deze figuurtjes. Controleproefpersonen zullen langer aarzelen (een langere reactietijd vertonen) bij figuurtjes met conflicterende productieregels. Wanneer iemand de impliciete (onbewuste) regels niet zomaar kan volgen en er daarom een keuze moet worden gemaakt welke van twee tegenstrijdige regels wordt verkozen, dan leidt dat tot een verlengde reactietijd. In ons onderzoek bleek dat anorexiapatiënten bij de niet-conflicterende figuurtjes sneller waren dan controles. Wanneer de conflicterende figuurtjes dienden te worden gekopieerd, dan bleek dat bij anorexiapatiënten even snel te gaan als bij niet-conflicterende, terwijl bij de controles het bekende effect van een verlengde reactietijd bij de conflicterende figuurtjes optrad.

$\mathrm{Na}$ gewichtsherstel zagen we geen normalisatie (dus verlenging van de reactietijd) bij de anorexiapatiënten: ze worden eerder (doch niet significant) nog wat sneller (verkorte reactietijd) wanneer hun gewicht normaliseert. Bij de controleproefpersonen zien we geen trainingseffect wanneer ze de test na ongeveer drie maanden opnieuw uitvoeren. Dit patroon is redelijk consistent over alle taken aanwezig.

De resultaten van deze studie vertonen dus een duidelijk patroon. We vinden geen verschil tussen de groepen in tekentijd (dus in de basale motorische snelheid). Wanneer we kijken naar de reactietijd die een weerslag is van cognitieve processen zoals planning van acties en bewegingen dan zijn anorexiapatiënten met sterk ondergewicht sneller. Daarbij komt dat anorexiapatiënten minder gehinderd worden door complexiteit, gebrek aan vertrouwdheid of conflict met impliciete tekenregels. We zien dus geen vertraging bij de anorexiapatiënten door ondergewicht, integendeel zelfs.

\section{Conclusie}

De bevindingen van dit onderzoek moeten voorzichtig worden geïnterpreteerd. Ze lijken in ieder geval niet in overeenstemming met de vaak gehoorde opvatting dat 
anorexiapatiënten met sterk ondergewicht een uitgesproken cognitief tekort vertonen. De resultaten lijken niet compatibel met de vaak genoemde aandachts- of geheugenproblemen bij deze patiënten. Er lijkt eerder sprake van een cognitieve 'sterkte' op het gebied van bijvoorbeeld planning van fijne bewegingen. Dat sluit natuurlijk niet uit dat deze patiënten (tegelijkertijd) ook cognitieve zwaktes kunnen vertonen. Problemen met 'set-shifting' (verandering van strategie), het wisselen tussen taken, of een gebrek aan flexibiliteit worden bij anorexiapatiënten bijvoorbeeld vaak beschreven (Southgate e.a., 2005; Tchanturia e.a., 2004). Mogelijk kunnen de resultaten begrepen worden als een reactiestijl die zich vooral richt op details en te weinig aandacht heeft voor het geheel. Een dergelijke stijl ziet men bijvoorbeeld bij mensen met autisme. Afhankelijk van de eisen van een taak zullen mensen met een dergelijke stijl goed of juist slecht gaan presteren. Ook een gebrek aan flexibiliteit zou bij simpele opdrachten een voordeel kunnen zijn...

Uit het feit dat de resultaten bij anorexiapatiënten gelijk blijven na gewichtsherstel zou men kunnen concluderen dat het gevonden effect eerder een duurzame trek is van deze patiënten dan een toestandsgebonden kenmerk, verbonden met het ondergewicht. Deze trek zou dan mogelijks een rol kunnen spelen bij de kwetsbaarheid voor het ontwikkelen van anorexia nervosa.

Deze bevindingen zijn in overeenstemming met de hypothese dat een sterke cognitieve activering, een 'mentale bewegingsdrang', karakteristiek is voor acute AN (Casper, 2006). Terwijl bij eenvoudige (semi-)uithongering motorische vertraging en energieverlies optreden, lijken anorexiapatiënten een alertheid te vertonen die gezien kan worden als de cognitieve tegenhanger van de vaak beschreven hyperactiviteit of 'bewegingsdrang' die (door sommigen) beschouwd wordt als een primair symptoom van de stoornis (Bergh \& Sodersten, 1996; Casper, 1998; Davis e.a., 1999). Mogelijk spelen zowel de hyperactiviteit als de verhoogde mentale activering een belangrijke rol in de psychopathologie van anorexia nervosa. Verder onderzoek is noodzakelijk naar deze 'gedragsactivatie', 'arousal', 'energie' of 'vitaliteit' die goed bekend is bij clinici. Dergelijk onderzoek is aan de gang.

\section{Literatuur}

Bergh, C. \& Sodersten, P. (1996). Anorexia nervosa, self-starvation and the reward of stress. Nature Medicine, 2, 21-22.

Bruch, H. (1973). Eating disorders: obesity, anorexia nervosa, and the person within. New York: Basic Books.

Casper, R.C. (1998). Behavioral activation and lack of concern, core symptoms of anorexia nervosa? International Journal of Eating Disorders, 24, 381-393.

Casper, R.C. (2006). The 'drive for activity' and 'restlessness' in anorexia nervosa: potential pathways. Journal of Affective Disorders, 92, 99-107.

Davis, C., Katzman, D.K. \& Kirsh, C. (1999). Compulsive physical activity in adolescents with anorexia nervosa: a psychobehavioral spiral of pathology. Journal of Nervous and Mental Disease, 187, 336-342.

Deth, R. van \& Vandereycken, W. (1988). Van vastenwonder tot magerzucht. Anorexia nervosa in historisch perspectief. Meppel/Amsterdam: Boom.

Pieters, G., Hulstijn, W., Maas, Y., Vandereycken, W., Probst, M. \& Sabbe, B. (in press). Psychomotor performance and sequence planning in anorexia nervosa before and after weight restoration. Eating and Weight Disorders.

Pieters, G., Hulstijn, W., Vandereycken, W., Maas, Y., Probst, M., Peuskens, J. \& Sabbe, B. (2005). Fast psychomotor functioning in anorexia nervosa: effect of weight restoration. Journal of Clinical and Experimental Neuropsychology, 27, 931-92.

Pieters, G., Maas, Y., Hulstijn, W., Vandereycken, W., Probst, M., Peuskens, J. \& Sabbe, B. (2004). Differentiation of cognitive and motor aspects in a digit symbol substitution test in anorexia nervosa patients, before and after weight restoration. Psychopathology, 37, 227-232.

Pieters, G., Sabbe, B., Hulstijn, W., Probst, M., Vandereycken, W. \& Peuskens, J. (2003). Fast psychomotor functioning in underweight anorexia nervosa patients. Journal of Psychiatric Research, 37, 501- 508.

Sabbe, B. \& Hulstijn, W. (2001). Psychomotor disturbances in schizophrenia and depressive disorders. Current Opinion in Psychiatry, 14, 597-603.

Sabbe, B., Hulstijn, W., Hoof, J. van, Tuynman-Qua, H.G. \& Zitman, F. (1999). Retardation in depression: assessment by means of simple motor tasks. Journal of Affective Disorders, $55,39-44$.

Southgate, L., Tchanturia, K. \& Treasure, J. (2005). Neuropsychological studies in eating disorders: a review. In P.I. Swain (Ed. ), Eating Disorders: new research. Hauppauge, NY: Nova Science Publishers.

Tchanturia, K., Anderluh, M.B., Morris, R.G., Rabe-Hesketh, S., Collier, D.A., Sanchez, P. \& Treasure, J.L. (2004). Cognitive flexibility in anorexia nervosa and bulimia nervosa. Journal of the International Neuropsychological Society, 10, 513-520. 